\title{
JUAN FRANCÉS DE IRIBARREN: CANTADAS DE NAVIDAD Y REYES PARA TIPLE DURANTE SU MAGISTERIO EN LA CATEDRAL DE MÁLAGA (1733-1767)
}

\section{Juan Francés de Iribarren: Treble Cantadas for Christmas and Epiphany during his Magistracy in Malaga's Cathedral (1733-1767)}

\author{
Laura LARA MORAL \\ Conservatorio Superior de Música de Málaga \\ laura.lara.moral.edu@juntadeandalucia.es
}

Fecha de recepción: 23/10/2019

Fecha de aceptación definitiva: 15/03/2020

RESUMEN: El origen y desarrollo estilístico de la cantada en España aún no ha sido objeto de un estudio científico lo suficientemente profundo; y, a tenor de los últimos avances realizados, queda mucho camino por recorrer. El presente artículo, centrado en el corpus compositivo de Juan Francés de Iribarren, muestra un análisis de sus cantadas de Navidad y Reyes para voz de tiple, donde confluyen aspectos históricos, musicales y literarios. Se trata de un autor de primer orden y, dado el reducido número de investigadores que le han prestado atención en las últimas décadas, con este estudio multidisciplinar se intenta aportar un nuevo impulso que contribuya a la recuperación y contextualización de las composiciones de este músico navarro del s. XVIII y, por extensión, de la música barroca española.

Palabras clave: Juan Francés de Iribarren; cantada; tiple; análisis; catedral; Málaga.

ABSTRACT: The cantada's origin and development in Spain has not yet been object of a scientific study deep enough; and, according to latest advances carried out, there is a long way to go. The present article, focused on the compositional work 
of Juan Francés de Iribarren, shows an analysis of his treble cantadas for Christmas and Epiphany, where historical, musical and literary and aspects converge. He is a first degree author and, given the small number of researchers who have paid him attention in recent decades, with this multidisciplinary study we try to give a new impetus that helps to the recovery and contextualization of these Navarrese musician's compositions from the Eighteenth century and, by extension, of the Spanish baroque music.

Key words: Juan Francés de Iribarren; cantada; treble; analysis; cathedral; Málaga.

\section{INTRODUCCIÓN}

El archivo musical de la catedral de Málaga alberga una ingente cantidad de piezas musicales que confiamos en que serán rescatadas, interpretadas y estudiadas algún día, hecho extrapolable al resto de la Península, en cuyos fondos duerme desde hace siglos gran parte de nuestro pasado musical. Durante más de treinta años, en la seo malagueña desempeñó el cargo de maestro de capilla uno de los músicos más prolíficos del Barroco español: Juan Francés de Iribarren, cuyo magisterio se extiende desde 1733 hasta 1767, sucediendo a Francisco Sanz ${ }^{1}$. Pero la obra de este autor de origen navarro no es solo llamativa por aspectos cuantitativos, sino que investigadores como Miguel Querol sostenían que sus composiciones eran de gran calidad, describiéndolo como «el más fecundo y perfecto compositor español de cantatas a solo y también el más original»².

Si bien podemos encontrar algunas de sus piezas en diferentes archivos de la geografía española y sudamericana, la inmensa mayoría de su legado musical se halla en la catedral de Málaga, de ahí que nuestro análisis se centre en composiciones custodiadas en este centro religioso ${ }^{3}$. Según uno de los últimos estudios realizados, la cifra de obras de Iribarren conservadas asciende a 907, 372 en latín y 535 en romance ${ }^{4}$.

Pese a que nuestro análisis está centrado en sus cantadas para tiple y, más concretamente, en aquellas dedicadas a la festividad de Navidad y Reyes ${ }^{5}$, este

1. NARANJo LoREnZO, Luis E. Trascripción de una selección de la obra de Juan Francés de Iribarren (1699-1767): estudio preliminary catálogo (inédito). Granada: Centro de Documentación Musical de Andalucía, 1997, p. 16.

2. Querol GaVAlDÁ, Miguel. «El cultivo de la cantata en España y la producción musical de Juan Francés de Iribarren (1698-1767)». Cuadernos de Sección. Música, 1983, 1, pp. 127-128.

3. NARANJO LORENZO, Luis E. Trascripción de una selección de la obra de Juan Francés de Iribarren..., op. cit., pp. 36-52.

4. LARA MORAL, Laura. Juan Francés de Iribarren: Las cantadas de Navidad de 1751. Trabajo final de máster inédito. Universidad de Granada, 2013, p. 64.

5. Además de los motivos que exponemos a continuación, sus cantadas de Navidad y Reyes para tiple suponen un excelente material objeto de estudio, ya que abarcan prácticamente la totalidad 
fecundo autor también compuso cantadas para el día del Corpus y la Concepción, aparte de alguna otra fecha destacada; no obstante, la fiesta de la Navidad era una de las más importantes del año litúrgico y muestra una mayor influencia de recursos teatrales ${ }^{6}$. Es más, la iglesia se llenaba de fieles y los maestros de capilla dedicaban mucho tiempo y esmero a la composición de estas piezas , de ahí que nos hayamos decantado por estas obras en concreto.

A esto debemos sumar que el antecesor de Iribarren, Francisco Sanz, no fue muy proclive a las nuevas tendencias compositivas que comenzaban a cultivarse en otras capillas a principios del s. XVIII, pues abogaba por la música «seria, según se practicaba en España»; con estas premisas, no es que se negara a cumplir con sus obligaciones, sino que «lo haría en aquel modo, rumbo y seriedad que él aprendió y practicó siempre», ya que "le repugnaban estas músicas nuevamente introducidas» ${ }^{8}$. He aquí un motivo más para subrayar la relevancia de estudiar las cantadas de Iribarren, pues todos los indicios nos llevan a suponer que serían estas las primeras piezas de este tipo escuchadas en la catedral de Málaga hasta el momento, dado el férreo rechazo que su antecesor mostraba hacia las nuevas modas e influencias extranjeras?

Pero, antes de continuar, conviene realizar ciertas aclaraciones en lo que a nomenclatura se refiere. Parece que los autores del s. XVIII no usaron el término "cantada" de manera muy coherente; según Cristóbal García, estos llamaron simplemente villancicos, arias (o áreas), dúos o duetos a muchas obras similares a las cantadas, lo que genera cierta confusión ${ }^{10}$. También Paulino Capdepón alude

de su magisterio en Málaga, lo que permite rastrear la evolución de su obra en muchos sentidos. Además, resulta muy interesante analizar qué tipo de cantores fueron los encargados de interpretar estas piezas pues, como veremos más adelante, Iribarren no contó con tiples adultos en plantilla durante todo su magisterio, algo que no ocurría con el resto de voces.

6. En el caso concreto de la catedral de Toledo, a esta teatralidad propia de los villancicos se sumaban tradiciones como la Sibila y los Pastores, escenificaciones contra las que luchaba el cabildo toledano durante el s. XVIII en un intento por prevenir los desórdenes que se producían; dichos altercados y alborotos son el origen de que las autoridades se plantearan incluso acabar con esta antigua tradición en 1750. MARTínez Gil, Carlos. La capilla de música de la Catedral de Toledo (1700-1764): evolución de un concepto sonoro. Toledo: Junta de Comunidades de Castilla La Mancha, 2003, p. 130.

7. García Gallardo, Cristóbal L. "Villancicos del s. XVIII en España». Música y Educación, 2009, 80, p. 79 .

8. A.C.M. (archivo catedral de Málaga), AA. CC. (actas capitulares) n. ${ }^{\circ} 44$, fol. (folio) 50r. $14-5-1728$

9. Si avanzamos en el tiempo, podemos afirmar que el único maestro de capilla de la catedral malagueña que compuso cantadas, en el sentido estricto de la palabra, durante el s. XVIII fue Juan Francés de Iribarren, pues su sucesor, Jaime Torrens, pese a componer villancicos de clara influencia italiana que incluían recitados y áreas, no utilizó la misma denominación, empleando indistintamente los términos "aria" o "villancico" para designar recitados o áreas a una o dos voces. MARTín QUIÑONES, M. á Ángeles. La música en la catedral de Málaga durante la segunda mitad del s. XVIII: La vida y obra de Jaime Torrens. Tesis doctoral inédita. Universidad de Granada, 1997, vol. 1, p. 466.

10. GARCía GALLARDO, Cristóbal L. La cantada religiosa de Juan Francés de Iribarren (1698-1767): análisis de Sagrada Devoción (1757). Granada: trabajo inédito de los cursos de doctorado, 1998, p. 5. 
a esta ambigüedad, pues «cuando el villancico incorpora las formas de la cantada italiana (recitado y aria) en el trascurso del s. XVIII, se confunden los términos villancico y cantada "11. De hecho, encontramos casos en los que una misma pieza se titula "cantada» en unas fuentes y «villancico» en otras, como podemos observar en algunas obras de Iribarren de su periodo malagueño (véanse Ilustraciones 1 y 2) ${ }^{12}$.

Lo cierto es que villancicos y cantadas son las dos grandes formas musicales de la música en castellano del s. XVIII y, según José López-Calo, ambas deberían ser tenidas en cuenta individualmente para su análisis ${ }^{13}$. Si nos remontamos a sus orígenes observaremos las primeras diferencias: mientras el villancico es una forma musical nacida en nuestro país durante la segunda mitad del s. Xv, que seguiría desarrollándose en los ss. XVI-XVII ${ }^{14}$, la cantada supone una forma musical de importación (originaria de Italia), que se introdujo en España a comienzos del periodo dieciochesco y, pese a lo novedoso de su irrupción, no consiguió eliminar ni sustituir al villancico hispano, aunque su influjo en este fue notable ${ }^{15}$.

En lo concerniente a las características formales de ambos géneros, podemos afirmar que, desde el s. XVII, el villancico tenía como elementos formales principales el estribillo y la copla, secciones no solo empleadas en el terreno sacro

11. Este autor define la cantada como un género musical derivado de la cantata italiana que surgió a finales del s. XVII y principios del s. XVIII; a diferencia del villancico y la tonada, de tradición española, la cantada se implantó en España como consecuencia de la influencia italiana sobre la nueva dinastía borbónica a inicios del s. XVIII. Es de contenido sacro, reservándose el término «cantada humana" para aquellas profanas, y está formada generalmente por recitado y aria, o bien dos recitados y dos arias. CAPDEPón Verdú, Paulino. "Cantada”. En CASARES Rodicio, Emilio (dir. y coor.). Diccionario de la música española e hispanoamericana. Madrid: Sociedad General de Autores y Editores, 1999, vol. 3, p. 72 .

12. Según J. J. Carreras, una misma pieza podía ser denominada de maneras distintas y de forma aparentemente contradictoria por las fuentes, que la clasificaban según su particular perspectiva, es por ello que "definir la cantata en el s. XVIII resulta una tarea poco menos que imposible». CARRERAS LóPEZ, Juan José. "La cantata española». En Leza Cruz, José Máximo (ed.). Historia de la música en España e Hispanoamérica (vol. 4). La música en el s. XVIII. Madrid: Fondo de Cultura Económica, 2014, p. 172.

13. López-CALO, José. La música en las catedrales españolas. Madrid: Instituto Complutense de Ciencias Musicales, 2012, p. 528.

14. Aunque el villancico se cultivó durante varios siglos, el sentido utilizado para este término variaría considerablemente del s. XV al XVII. Durante los ss. XVI y XVII el término se fue desprendiendo de su sentido estructural original de forma literaria y musical específica, convirtiéndose así en un término genérico que englobaba todo tipo de composición vocal en romance interpretada en un contexto sagrado. Aún predominaba la estructura básica de estribillo y coplas en el villancico, característica extrapolable a otras composiciones vocales profanas que no recibían el nombre de villancicos, sino el de tonos o letras. Así pues, la fórmula estribillo-coplas constituía un factor definitorio del villancico, que era común a todos los géneros vocales en romance, ya fueran compuestos para la iglesia, el teatro o la cámara. A partir de principios del s. XVII, el villancico ya no se definía por su forma sino por su función. GONZÁlez VAlle, José V. "Música litúrgica con acompañamiento orquestal, 1750-1800». En BoyD, Malcolm y Carreras López, Juan José (eds.). La música en España en el s. XVIII. Madrid: Cambridge University Press, 2000, pp. 88-89.

15. López-Calo, José. La música en las catedrales españolas..., op. cit., pp. 528-529. 
(villancicos polifónicos barrocos y tonos a solo «a lo divino»), sino en el profano, como era el caso del tono humano. Estas secciones no desaparecerían en el villancico dieciochesco, sino que este género incorporaría rasgos estilísticos modernos, surgiendo de esta manera un nuevo tipo formal que incluía recitados y arias, aunque también minuetos o fugas; dicha hibridación entre secciones tradicionales y modernas daría lugar a una forma musical autónoma dentro del género del villancico denominada "cantata» o "cantada»" Del mismo modo que el estilo operístico italiano se introdujo en la zarzuela o el tono humano, el villancico también lo adoptó, al ser un género que cultivaban los mismos compositores ${ }^{17}$.

La cantata, de origen profano, se adaptó así al ámbito religioso en España, dando lugar a un amplísimo repertorio de música devocional, pero la persistencia del término tradicional "villancico» ocultaría su existencia en cierta medida ${ }^{18}$. Es más, el uso generalizado de esta denominación autóctona ha dificultado que la cantada hispánica fuese tenida en cuenta en estudios sobre los géneros vocales europeos de la época, impidiendo que esta gozara hoy de un lugar más destacado en el panorama musical europeo ${ }^{19}$. Esta pervivencia del término en España se refiere principalmente al ámbito institucional eclesiástico, en el que primaba la función religiosa sobre aspectos musicales concretos a la hora de denominar estas piezas ${ }^{20}$.

Llegados a este punto, debemos aclarar que el género de la cantada distinguía entre cantadas humanas o profanas y sacras, siendo los compositores quienes especificaban en el encabezamiento de sus partituras el ámbito para el que eran compuestas; pero las diferencias entre la cantada profana y sacra resultaron ser, en el caso español, mínimas. De hecho, no era infrecuente en nuestro país adaptar "a lo divino" cantatas profanas españolas e italianas ${ }^{21}$. No obstante, mientras la cantada humana española desaparecería en la segunda mitad del s. XVIII, en el ámbito sacro perduraría a lo largo de toda la centuria y, según investigaciones recientes, el cultivo de la cantada sacra española fue amplísimo, pese a que aún está por estudiar ${ }^{22}$.

16. TORRENTE SÁNCHEZ-GUISANDE, Álvaro. "La modernización/italianización de la música sacra». En Leza Cruz, José Máximo (ed.). Historia de la música en España e Hispanoamérica (vol. 4). La música en el s. XVIII. Madrid: Fondo de Cultura Económica, 2014, pp. 127 y 134.

17. GonZÁlez VAlle, José V. "Música litúrgica con acompañamiento orquestal, 1750-1800»..., op. cit., p. 89.

18. CARreras López, Juan José. "La cantata española»..., op. cit., pp. 172-173.

19. González Valle, José V. "Música litúrgica con acompañamiento orquestal, 1750-1800»..., op. cit., p. 87.

20. Carreras López, Juan José. «La cantata española»..., op. cit., p. 178.

21. Ibid., pp. 173 y 175.

22. Ibid., pp. 178 y 182. 


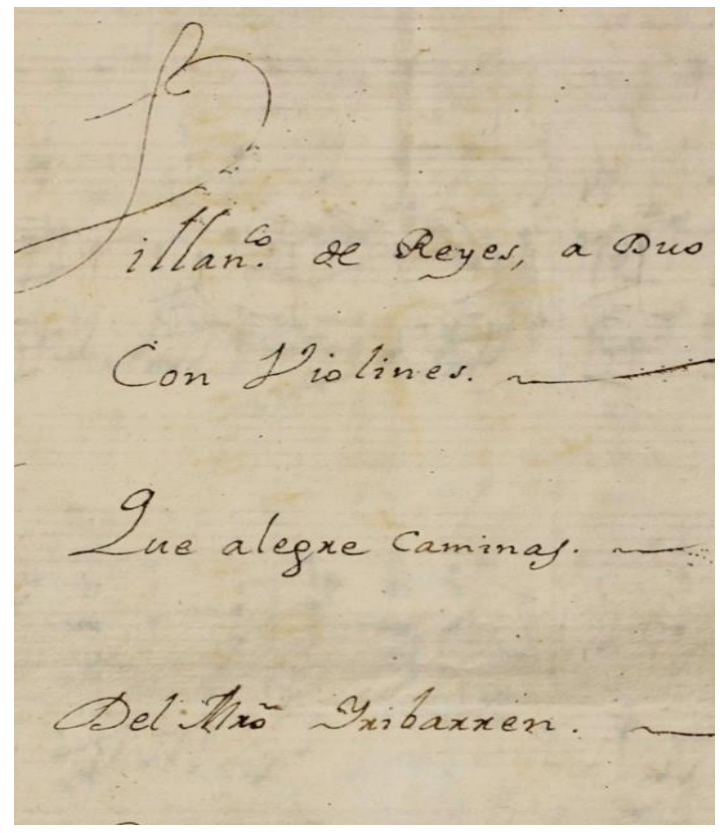

Ilustración 1. Portada de la pieza Qué alegre caminas, titulada «villancico». A.C.M., sig. (signatura) 102-1 (sección música).

Como hemos podido comprobar en los párrafos anteriores, existe cierta controversia en cuanto a la terminología empleada en este tipo de repertorio ${ }^{23}$, pero, en el caso del maestro navarro, hemos denominado "cantadas" a aquellas piezas que cumplen tres premisas: compuestas para una o dos voces ${ }^{24}$, formadas por recitados y/o áreas y, por último, que incluyan el término "cantada" en el manuscrito/ borrador o en la particella. Las partituras originales de estas obras seleccionadas

23. Para obtener más información sobre el género de la cantada y el villancico véase JAMBOU, Louis. "Cantatas solísticas de Valls y compositores anónimos. Identidad y ruptura estilística. Apuntes para un estudio». Revista de Musicología, 1995, vol. 18, pp. 291-325; Bonastre Bertrán, Francesc. "Els orígens del concepte de barroc musical hispànic, a l'entorn del centenari de l'Institut d'Estudis Catalans: Felip Pedrell, Higini Anglès, Miguel Querol». Recerca Musicològica, 2007-2008, XVII-XVIII, pp. 41-65; CARreras López, Juan José. La música en las catedrales durante el s. XVIII. Francisco J. García "El Españoleto» (1730-1809). La Rioja: Institución Fernando el Católico, 1983.

24. A diferencia de Iribarren, cuyas cantadas solo incluyen una o dos voces, el compositor Jayme de la Tê compuso 253 cantatas (corpus musical que incluye cantadas tanto profanas como religiosas) y un reducido número de ellas fueron compuestas para tres o cuatro voces. DODERER, Gerhard. "Un repertorio desconocido: las cantadas de Jayme de la Tê y Sagau (Lisboa, 1715-1726)». En Boyd, Malcolm y Carreras López, Juan José (eds.). La música en España en el s. XVIII. España: Cambridge University Press, 2000, p. 99. 
se encuentran en el archivo de la catedral de Málaga (sección música) y, salvo contadas excepciones, el paso de los siglos no ha supuesto un deterioro irrevocable ${ }^{25}$.

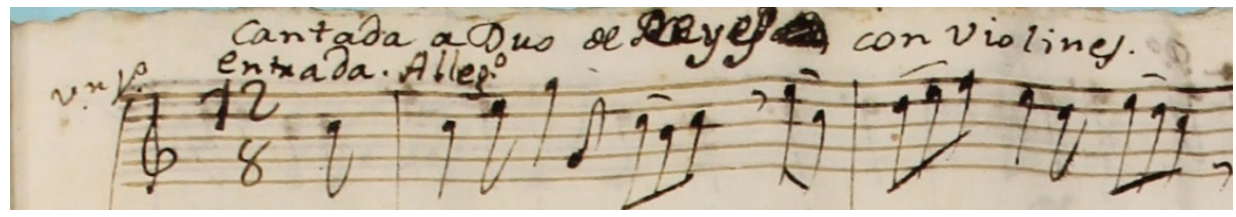

Ilustración 2. Parte superior de la primera página de la pieza Qué alegre caminas, titulada "cantada». A.C.M., sig. 102-1 (sección música).

\section{LOS «NO TIPLES» DURANTE EL MAGISTERIO DE IRIBARREN}

El título de este epígrafe ilustra en pocas palabras la situación de la prebenda de tiple durante el magisterio de este compositor navarro. Si bien en el presente artículo nos hemos centrado en sus cantadas para tiple de Navidad y Reyes, lo cierto es que nunca hubo cantores que ocupasen este puesto durante dicho periodo; por lo tanto, debió ingeniárselas para suplir esta carencia vocal que sufría por aquel entonces la capilla catedralicia malagueña.

Tomás López Sainz fue el último cantante en ocupar la prebenda de tiple antes de la llegada de Juan Francés de Iribarren a dicha institución religiosa; la muerte de este cantor se produjo en 1732, momento en el que se iniciaría una larga etapa caracterizada por la falta de tiples en la catedral malacitana ${ }^{26}$. De hecho, habría que esperar hasta 1770 para que fuese contratado Pablo Blasco, quien desempeñó esta labor hasta $1778^{27}$. Aunque resulte llamativa esta situación, "la búsqueda de tiples fue una tónica general en las catedrales españolas y en la documentación conservada se pone de manifiesto la escasez y dificultad que suponía contar con buenos tiples» ${ }^{28}$.

Como consecuencia, los centros religiosos se veían obligados a suplir esta vOz con otros cantantes de la capilla y una de las alternativas era encomendarlo a los seises $^{29}$. Pese a que lo lógico era que estos niños cantores interpretaran el papel de

25. Algunas piezas como la cantada Ave que deja el nido, A.C.M., sig. 75-13 (sección música), no pueden ser consultadas por encontrarse en proceso de restauración.

26. A.C.M., AA. CC. n. ${ }^{\circ} 44$, s. p. (sin paginar), 7-11-1732.

27. MARTín QuiÑones, M. ${ }^{a}$ Ángeles. La música en la catedral de Málaga durante la segunda mitad del s. XVIII..., op. cit., vol. 1, p. 168.

28. MARTín MÁrqueZ, Alberto. Niños y tiples en la catedral de Zamora (1600-1750). Aproximación a su estudio. Zamora: Festival Internacional de Música "Pórtico de Zamora», 2008, p. 4.

29. En un documento normativo que atañe a la capilla musical de Málaga, fechado hacia 1640, y aún vigente durante el magisterio de Iribarren, se dice que «de los seises suele haber cuatro, de nueve a diez años arriba, que tengan buenas y delicadas voces, los cuales cantan los tiples cuando hay canto 
tiple antes del periodo de muda, existen casos como el de Pedro Rodríguez que, tras cambiar la voz, cantaba con los contraltos y tiples siempre que era necesario, aunque, a efectos salariales, seguía ocupando la plaza de seise ${ }^{30}$.

Otra alternativa serían las voces de contraltos, pues las reuniones capitulares también dejaron constancia de la versatilidad vocal de algún cantor de esta cuerda que, según las necesidades de la capilla, interpretaba el papel de tiple ${ }^{31}$. Como ejemplo de ello encontramos los casos de los contraltos José de Juan o Miguel Castroverde, que suplían a los tiples siempre que la ocasión lo requería ${ }^{32}$.

Una tercera opción, algo más insólita, era asignar estos papeles de tiple a tenores. Prueba de esta hipótesis sería una enigmática anotación en la última página de la cantada de Iribarren Hola Jau ah Riselo (1751). En esta partitura general, el propio compositor dejó escritos dos nombres abreviados, como podemos ver en la siguiente ilustración:

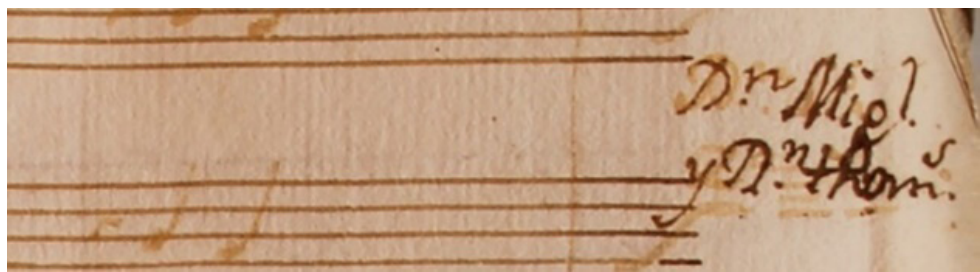

Ilustración 3. Fragmento de la última página de la partitura general de la cantada Hola Jau ah Riselo (1751). A.C.M., sig. 76-16 (sección música).

Tras el cotejo de las fuentes de la época, hemos descubierto que dichos nombres coinciden con dos cantantes que estaban desempeñando el cargo de contralto y de tenor en la capilla. Probablemente, estos se corresponden con Miguel Barea, tenor que ejercía desde $1751^{33}$, y Tomás García, contralto que pasó a formar parte de la capilla en $1745^{34}$. A esto se suma la ausencia de instrumentistas o seises que estuviesen ejerciendo aquel año en la catedral malagueña y que, además, coincidiesen con dichos nombres; lo que nos permite afirmar que Iribarren dejó

de órgano en el coro y fuera de él, en las chanzonetas». A.C.M., leg. (legajo) 363, pza. (pieza) 8, fol. (folio) 138r. Libro de todas las ceremonias que se guardan en esta Santa Iglesia de Málaga, según ordenación becha por el Ilustrísimo y Reverendísimo Sr. Fr. Antonio Enríquez de Porres, obispo de Málaga (libro manuscrito fechado en torno a 1640).

30. A.C.M., AA. CC. n. ${ }^{\circ} 49$, fol. 236v., 23-12-1760.

31. Se menciona que Luis Cano pretendía la plaza de tiple vacante que había gozado Juan Osorio, "contralto atiplado». A.C.M., AA. CC. n. ${ }^{\circ} 49$, fol. 614v., 17-8-1763.

32. Si bien la voz de Castroverde era de contralto, este comentaba que suplía a los tiples siempre que era necesario, como lo hizo José de Juan en su tiempo. A.C.M., AA. CC. n. ${ }^{\circ} 46$, fols. 143v. y 144r., 29-7-1744.

33. A.C.M., AA. CC. n. ${ }^{\circ} 46$, fol. 988r., 11-9-1751

34. A.C.M., AA. CC. n. ${ }^{\circ} 46$, fol. 383r., 4-8-1745. 
plasmado en su partitura los cantantes que interpretaban esta pieza, hecho insólito que no hemos encontrado en el resto de obras analizadas.

Una vez resuelta la cuestión sobre el cargo que desempeñaban ambos músicos, se nos plantea un nuevo interrogante en torno a la asunción del papel de tiple. En primer lugar, es lógico pensar que el tenor hiciese el papel de alto y, por consiguiente, el alto ejecutase la parte de tiple, teniendo en cuenta la cercanía en las tesituras. Sin embargo, creemos que el orden en el que son citados ambos músicos (Miguel, en la parte superior y Tomás, en la inferior) puede estar relacionado con la disposición de la partitura en sí, estando el pentagrama del tiple por encima del de alto. Esto nos lleva a decantarnos por una segunda hipótesis, en la que el tenor Miguel Barea haría las veces de tiple, mientras que a Tomás García le correspondería su papel natural de alto.

Además de este detalle mencionado, para fundamentar esta segunda suposición debemos señalar varios factores que la convierten en la opción más plausible. Por una parte, hemos observado que el propio Iribarren compuso la cantada Quién me dirá (1733) para dos tenores y, en la portada de las particellas, señalaba que "pueden cantarla dos tiples aunque son claves de tenor" ${ }^{35}$; así pues, si un tiple podía interpretar un papel originalmente escrito para tenor, es más que probable que esto mismo ocurriese a la inversa.

Por otra parte, el análisis de las tesituras de estas cantadas de Navidad y Reyes nos permite confirmar que las voces de tenor y tiple tenían un rango melódico bastante similar que, con un simple cambio de octava, permitiría que pudiesen suplirse los unos a los otros en caso de necesidad. A esto se suma la conservación de fuentes, algo posteriores a la época de Iribarren, en las que se menciona que "los tenores en todas partes cantan los papeles de tiple supliendo por estos en las ocasiones que lo exige la necesidad, 36 .

Según los datos reflejados en las reuniones capitulares de la seo malagueña, otros posibles sustitutos de esta voz de tiple eran los instrumentos de registro agudo. En primer lugar, llama nuestra atención un acta capitular de 1706 donde se afirma que José Ferro, violón y violín de la capilla malacitana, sería de mucha utilidad tanto para los acompañamientos como para suplir la voz de tiple ${ }^{37}$. Aunque este instrumentista no ejerció durante el magisterio del maestro navarro, es más que probable que esta práctica siguiera vigente en la época en la que nos centramos; no obstante, no hemos hallado pruebas de violinistas a los que se les encomendara la parte de tiple en dicha etapa. Otro hecho reseñable es que Juan Cotillas, que hasta 1733 ejercía como bajonista en la capilla malagueña, pedía aquel mismo año entrar en el

35. A.C.M., sig. 77-23 (sección música).

36. Se conserva un informe de Jaime Torrens sobre el aspirante a tenor José Blasco, en el que afirmaba que los tenores cantaban los papeles de tiple siempre que fuese necesario, lo que le convertía en un candidato muy útil para la capilla. A.C.M., leg. 576, pza. 14, 30-10-1787.

37. A.C.M., AA. CC. n. ${ }^{\circ}$ 39, fol. 117r., 7-5-1706. 
coro con el oboe ante la falta que había de tiples ${ }^{38}$, evidencia de la versatilidad que llegaron a mostrar muchos instrumentistas de la época.

\section{ASPECTOS MUSICALES GENERALES DE LAS OBRAS SELECCIONADAS}

Ya en la introducción dejábamos claro qué criterios seguir para denominar a una obra de Iribarren "cantada"; no obstante, el número de piezas que se ajustan a estas premisas es una cifra inabarcable en un estudio de estas dimensiones. Como consecuencia, nuestro trabajo se ha limitado a aquellas cantadas compuestas para la festividad de Navidad y Reyes y que, además, implican la voz de tiple, cuyos títulos y otros datos se recogen a continuación:

TABla 1. CANTADAS SELECCIONADAS PARA EL PRESENTE ESTUDiO (CONSERVADAS EN A.C.M.)

\begin{tabular}{|l|c|c|c|}
\hline \multicolumn{1}{|c|}{ TítulO39 } & SignATURA & $\begin{array}{c}\text { VOZ O VOCES } \\
\text { IMPLICADAS }\end{array}$ & $\begin{array}{c}\text { AÑO DE } \\
\text { COMPOSICIÓN }\end{array}$ \\
\hline Quién me dirá & Sig. 77-23 & SS $^{41}$ & 1733 \\
\hline Tortolilla qué amorosa & Sig. 78-16 & ST & $1733^{42}$ \\
\hline Has oído Fenisa & Sig. 76-12 & SS & 1735 \\
\hline A Belén caminad & Sig. 75-4 & SA & 1736 \\
\hline Fogosa inteligencia & Sig. 76-11 & S & 1737 \\
\hline iOh! bienaventurada & Sig. 77-7 & S & 1738 \\
\hline Que habréis primero & Sig. 77-19 & SS & 1741 \\
\hline Qué alegre caminas & Sig. 102-1 & SA & 1744 \\
\hline Qué temprano joh! bien mío & Sig. 77-22 & S & 1746 \\
\hline Hola Jau ah Riselo & Sig. 76-16 & SA & 1751 \\
\hline Pardiobre & Sig. 77-11 & S & 1751 \\
\hline
\end{tabular}

38. A.C.M., AA. CC. n. ${ }^{\circ} 44$, s. p., 24-7-1733.

39. En todos estos títulos se ha normalizado la ortografía.

40. Empleamos las siguientes abreviaturas: S (tiple), A (alto), T (tenor) y B (bajo).

41. Como ya hemos mencionado, aunque esta pieza es original para dos tenores, en la portada de su particella se indica que "pueden cantarlo dos tiples, aunque son las claves de tenor". Es por ello que hemos querido incluirla en nuestro estudio.

42. Esta cantada fue compuesta para la festividad de Reyes. Cuenta con un juego de particellas de 1733 y otro de 1737 , y el manuscrito de la partitura tiene la fecha tachada y sobre ella está escrito 1734 . 
JUAN FRANCÉS DE IRIBARREN: CANTADAS DE NAVIDAD Y REYES PARA TIPLE DURANTE SU MAGISTERIO...

\begin{tabular}{|l|c|c|c|}
\hline \multicolumn{1}{|c|}{ TÍtUlO } & SIgNATURA & $\begin{array}{c}\text { VOZ O VOCES } \\
\text { IMPLICADAS }\end{array}$ & $\begin{array}{c}\text { AÑO DE } \\
\text { COMPOSICIÓN }\end{array}$ \\
\hline Per Maria gratia plena ${ }^{43}$ & Sig. $77-12$ & S & 1753 \\
\hline Respira Adán & Sig. $78-1$ & S & 1753 \\
\hline Ya joh! gran naturaleza & Sig. $78-22$ & S & 1757 \\
\hline Hombres prevenid & Sig. $76-18$ & S $^{44}$ & 1758 \\
\hline Por aquel horizonte $^{45}$ & Leg. 295 & S & 1759 \\
\hline
\end{tabular}

Como podemos deducir de los datos expuestos en la tabla anterior, Iribarren compuso cantadas de Navidad y Reyes para tiple durante todo su magisterio en la catedral de Málaga, pues fue admitido en 1733 y, aunque su muerte no tuvo lugar hasta 1767, sus últimos años fueron menos prolíficos por causas de salud ${ }^{46}$. No obstante, se observan algunos periodos en los que evitó usar este tipo de voces, como 1739-40, 1747-50 o 1754-56. La principal hipótesis que podría plantearse es que en aquellos años no contó con voces de tiple que realizaran dicho papel; pero, como hemos señalado en epígrafes anteriores, lo cierto es que durante todo su magisterio tuvo que lidiar con esta dificultad, pues la prebenda de tiple nunca se cubrió.

Del mismo modo, es reseñable que, si bien compuso dúos (tres piezas para dos tiples; tres, para tiple y alto; o una, para tiple y tenor), nueve de las dieciséis cantadas analizadas son para tiple solo. Teniendo en cuenta la ausencia de estos cantores durante su magisterio, es obvio que implicar dos voces agudas en una misma pieza sería algo arriesgado por su parte; pero tampoco suponen una cifra muy elevada aquellos dúos para tiple y alto o tiple y tenor, lo que nos lleva a suponer su preferencia por cantadas a solo. Esta hipótesis es confirmada si ampliamos nuestro campo de estudio, ya que, observando el resto de sus cantadas para Navidad y Reyes, inclusive aquellas que no son para tiple, solo diez de las cuarenta y tres piezas que conforman este corpus compositivo son para dos voces, mientras el resto son para una sola voz.

43. Aunque en la fuente musical se la denomina "cantada", en el pliego impreso en la Navidad de aquel año se la titula "villancico». Encontramos una copia del pliego original en ALVAR EzQUERRA, Manuel. Villancicos dieciochescos. Edición facsímil. Málaga: Ayuntamiento de Málaga, 1973.

44. Esta pieza era para tiple solo, pero, al comienzo de su "canción", Iribarren indicaba que puede intervenir un segundo tiple a unísono con el primero en la repetición de las coplas. Puesto como este segundo tiple no tenía una parte musical propia, sino que simplemente cantaba a unísono con el primero, hemos catalogado esta pieza como para tiple solo.

45. La trascripción de esta pieza está publicada en Querol Gavaldá, Miguel (ed.). Música barroca española (vol. 5): Cantatas y canciones para voz solista e instrumentos (1640-1760). Barcelona: Instituto Español de Musicología, 1973, pp. 59-67.

46. NARANJO LORENZO, Luis E. Trascripción de una selección de la obra de Juan Francés de Iribarren..., op. cit., p. 18. 
En lo que a aspectos tonales se refiere, el análisis de las piezas escogidas en este artículo arroja ciertos datos relevantes. Por una parte, este compositor, como algunos de su época ${ }^{47}$, evita exceder de dos o tres alteraciones en la armadura. Este hecho tiene su origen en el proceso de transición que atravesaba la armonía de la época, pasando del sistema modal al tonal; por otra parte, las limitaciones técnicas de muchos de los instrumentos empleados propiciaban el uso reducido de alteraciones accidentales ${ }^{48}$. Otro detalle destacable es la no concordancia entre la tonalidad real de la pieza y la armadura que encontramos en algunos casos, ya que, en tonos que requieren más de dos bemoles o sostenidos, para completar dicha armadura aparecen estas alteraciones ausentes como accidentales ${ }^{49}$.

Según Joel Lester, esta desconexión entre la armadura y la tonalidad real de las piezas son ejemplos de «armaduras dóricas", empleadas por autores dieciochescos como Rameau, J. S. Bach e incluso, ya a comienzos del s. XIX, Beethoven ${ }^{50}$. Una de las razones para mantener estas armaduras era el desacuerdo imperante entre los músicos en el s. XVIII sobre qué alteraciones pertenecían realmente a la armadura en los tonos menores; según el autor francés François Campion (ca. 1868-1748), la escala menor debía ser dórica (con el sexto grado rebajado de manera accidental, no como parte de la armadura $)^{51}$.

Respecto a la plantilla instrumental, las cantadas analizadas pueden clasificarse en varias tipologías: el grupo más numeroso son aquellas para voz, continuo y dos violines, cuya cifra asciende a diez; a estas debemos sumar dos que implican voz, continuo, dos violines y oboe ${ }^{52}$; una para voz, continuo, dos violines y flau$\mathrm{ta}^{53}$; otra para voz, continuo, dos flautas dulces y dos oboes ${ }^{54}$; otra para voz, violines, continuo y dos trompas ${ }^{55}$; y, como caso excepcional, una para voz, continuo

47. M. ${ }^{a}$ Ángeles Martín sostiene que en los villancicos de la segunda mitad del s. XVIII, por norma general, destacan tonalidades con escasas alteraciones. MARTín QuiÑONES, M. ${ }^{a}$ Ángeles. La música en la catedral de Málaga durante la segunda mitad del s. XVIII..., op. cit., vol. 1, p. 473. $138-141$

48. TORRenTe, Álvaro. "La modernización/italianización de la música sacra»..., op. cit., pp.

49. Este fenómeno es muy frecuente en los recitados y, sin embargo, en las áreas solo encontramos algunos ejemplos en los que se produce esta no concordancia entre tonalidad y armadura, como es el caso del área de las cantadas Has oído Fenisa (primer área) y Ya anticipo la alegre primavera, cuya tonalidad es claramente sol menor aunque en la armadura solo encontramos un bemol; o, por otra parte, las cantadas Fogosa inteligencia y Ya joh! gran naturaleza, cuyo tono principal es do menor aunque en su armadura solo haya dos bemoles.

50. LESTER, Joel. Compositional theory in the Eighteenth Century. Estados Unidos: Harvard University Press, 1996, p. 59.

51. LESTER, Joel. Bach's Works for Solo Violin: Style, Structure, Performance. Nueva York: Oxford University Press, 1996, p. 14.

52. Se trata de las piezas Tortolilla qué amorosa (1733) y Pardiobre (1751).

53. Hola Jau ab Riselo (1751).

54. Ya job! gran naturaleza (1757).

55. Hombres prevenid (1758). 
y dos flautas ${ }^{56}$. Aunque hay algún caso temprano en el que se introduce un oboe, como la cantada de 1733 Tortolilla qué amorosa, el empleo de instrumentos de viento es mucho más recurrente en aquellas obras compuestas a partir de 1751.

Centrándonos a continuación en aspectos formales, en la siguiente tabla especificamos las secciones internas que conforman estas obras:

TABla 2. SECCIONES QUE FORMAN LAS CANTADAS

\begin{tabular}{|l|r|r|}
\hline \multicolumn{1}{|c|}{ COMBINACIONES DE SECCIONES $^{\mid}$} & $\begin{array}{r}\text { N. }{ }^{\circ} \text { DE } \\
\text { OBRAS }\end{array}$ & $\begin{array}{r}\text { AÑOS DE } \\
\text { COMPOSICIÓN }\end{array}$ \\
\hline RECITADO/ÁREA $^{57}$ & 6 & $\begin{array}{r}1746,1751,1751, \\
1753,1757 \text { y } 1759\end{array}$ \\
\hline RECITADO/ÁREA/RECITADO/ÁREA $^{58}$ & 4 & $\begin{array}{r}1735,1737,1738 \\
\text { y } 1741\end{array}$ \\
\hline INTRODUCCIÓN/RECITADO/ÁREA $^{59}$ & 1 & 1753 \\
\hline RECITADO/CANCIÓN $^{60}$ & 1 & 1758 \\
\hline ENTRADA/RECITADO/ÁREA/RECITADO/FINAL $^{61}$ & 1 & 1743 \\
\hline INTRODUCCIÓN/RECITADO/ÁREA/RECITADO/ÁREA $^{62}$ & 1 & 1736 \\
\hline $\begin{array}{l}\text { INTRODUCCIÓN/RECITADO/ÁREA/RECITADO/ } \\
\text { ÁREA/RECITADO }\end{array}$ & 1 & 1 \\
\hline $\begin{array}{l}\text { INTRODUCCIÓN/RECITADO/ÁREA/RECITADO/ } \\
\text { PASTORELA }\end{array}$ & & 1736 \\
\hline
\end{tabular}

A tenor de los datos expuestos en la tabla anterior, parece que la estructura más utilizada por Iribarren en estas cantadas es la que incluye un solo recitado y un área. Pero lo realmente llamativo es la fecha de composición de estas seis piezas, pues abarca desde el año 1746 (Qué temprano job! bien mí) hasta 1759 (Por

56. Por aquel horizonte (1759).

57. Qué temprano job! bien mío (1746), Hola Jau ah Riselo (1751), Pardiobre (1751), Respira Adán (1753), Ya job! gran naturaleza (1757) y Por aquel horizonte (1759).

58. Has oído Fenissa (1735), Fogosa inteligencia (1737), jOb! bienaventurada (1738) y Qué habréis primero (1741).

59. Per Maria gratia plena (1753).

60. Hombres prevenid (1758).

61. Qué alegre caminas (1744).

62. Quién me dirá (1733).

63. Tortolilla que amorosa (1733)

64. A Belén caminad (1736). 
aquel horizonte); dato que contrasta con la fecha de composición de sus cantadas más extensas y con mayor número de secciones internas, que son obras mucho más tempranas.

Como resultado de este cotejo entre la fecha de composición y número de movimientos o secciones que conforman sus cantadas, resulta evidente que, a medida que nos acercamos a mediados del s. XVIII, las piezas analizadas reducen sensiblemente el número de movimientos internos que las componen ${ }^{65}$. A continuación expondremos algunas de las características musicales más representativas de los diversos tipos de secciones que encontramos en las cantadas analizadas.

\subsection{Recitados}

En cuanto a su instrumentación, observamos que casi todos los recitados analizados en el presente artículo son recitados semplices o $\operatorname{seccos}^{66} \mathrm{O}$, en otras palabras, son secciones cuya voz o voces solo están sustentadas por el bajo continuo ${ }^{67}$. Como excepción encontramos las cantadas Hola Jau ab Riselo y Ya job! gran naturaleza, en cuyos recitados Iribarren inserta dos violines.

Este segundo tipo de recitados son catalogados como accompagnato o stromentato $^{68} \mathrm{y}$, debido a que el número de intérpretes aumenta, la libertad de las voces se ve reducida drásticamente. De hecho, en el recitado de la cantada Ya job! gran naturaleza aparece la indicación "a compás», lo que sugería un tempo estable $^{69}$.

\section{2. Áreas}

En estos movimientos hemos observado ciertos patrones formales y armónicos que deben ser destacados. Salvo dos excepciones que veremos más adelante,

65. De hecho, resulta curioso que, en el caso de los villancicos, formados por estribillos y coplas, la tendencia en el s. XVIII fue imponer a los maestros no cantar todas las coplas, de manera que no se prolongara innecesariamente la celebración litúrgica de los maitines; de ahí que no resulte extraño esta tendencia a la simplificación también en el caso de las cantadas. López-CALO, José. La música en las catedrales españolas..., op. cit., p. 528.

66. WeSTRUP, Jack. "Recitativo». En SADIE, Stanley (ed.). The New Grove Dictionary of Music and Musicians. 6. a edición. Londres: MacMillan Publishers Limited, 1980, vol. 15, pp. 645-646.

67. En este tipo de recitados solo participan como acompañamiento un instrumento polifónico que realiza el continuo, como el arpa o el órgano (desplegando las armonías indicadas por el bajo cifrado) y un instrumento grave monofónico, como el violón o bajón, que refuerza la voz grave.

68. WeSTRUP, Jack. «Recitativo»..., op. cit., pp. 645-646.

69. A diferencia del recitado secco, este tipo de recitado incluye otros instrumentos no propios de la realización del continuo, como son los violines; lo cual, sin lugar a dudas, dificultaría la compenetración rítmica del conjunto vocal-instrumental en caso de que el cantante se tomase demasiadas libertades. 
sus áreas muestran simultáneamente tanto una macroforma como una microforma determinada: siguen un esquema tripartito a grandes rasgos, ya que son áreas da capo o, como citan algunos autores, "áreas napolitanas" ${ }^{70}$; pero también muestran una estructura interna más compleja denominada pentapartita, algo más avanzada que la tripartita ${ }^{71}$. Este tipo de áreas divididas en cinco partes también son denominadas por M. ángeles Martín «áreas sonata” o "áreas con sección de desarrollo", las cuales, a partir de 1770, comenzaban a desbancar al área da capo ${ }^{72}$.

Como podemos ver en la siguiente tabla, la sección A se subdivide a su vez en cinco subsecciones; las zonas denominadas R1, R2 y R3 son ritornellos instrumentales, mientras que A1, A2 y B son secciones vocales-instrumentales.

TABLA 3. ESTRUCTURA INTERNA GENERAL DE LAS ÁREAS ANALIZADAS

\begin{tabular}{|l|l|c|c|c|c|c|c|}
\hline Macroforma & \multicolumn{5}{|c|}{ A } & B & A' ("d. c.”) \\
\hline Microforma & R1 & A1 & R2 & A2 & R3 & B & A' ("d. c.”) \\
\hline
\end{tabular}

Estas áreas comienzan con un ritornello instrumental denominado R1, en el que suele aparecer el motivo melódico principal que la voz retoma en la siguiente sección (A1 ${ }^{73}$. En cuanto a la formación del material temático, un gran porcentaje de estas introducciones instrumentales se compone de antecedente/progresión/ cadencia. El siguiente ejemplo es muestra de ello:

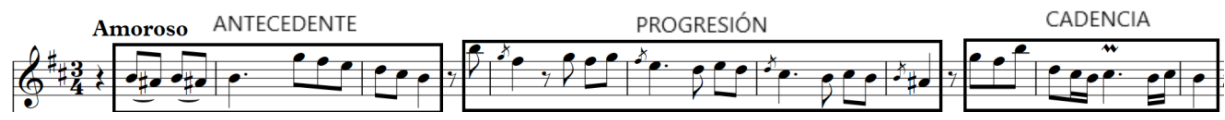

Ilustración 4. Motivo principal del área de la cantada Hola Jau ah Riselo, parte de flauta travesera, cc. (compases) 1-9.

70. Esta forma tripartita es también denominada «aria napolitana». CAPDEPÓN VERDú, Paulino. "Cantada"..., op. cit., p. 72. Y María Gembero destaca que esta forma da capo en las áreas de Iribarren es un reflejo de su asimilación del lenguaje teatral en la música religiosa, tendencia que se generalizaría en las catedrales españolas durante la segunda mitad del s. XVIII. GEMBERO Ustárroz, María. Navarra/ Música. Navarra: Gobierno de Navarra, Departamento de Cultura, Deporte y Juventud y Dirección General de Cultura-Príncipe de Viana, 2016, p. 133.

71. Westrup, Jack; McClymonds, Marita P.; Budden, Julian y Clemens, Andrew. "Aria». En SAdie, S. y TYrrel, J. The New Grove Dictionary of Music and Musicians [en línea], 2001 [consulta 22-10-19]: https://doi.org/10.1093/gmo/9781561592630.article.43315.

72. MARTín QuiÑones, M. ${ }^{a}$ Ángeles. La música en la catedral de Málaga durante la segunda mitad del s. XVIII..., op. cit., vol. 1, p. 483.

73. Si bien en algunos casos no se utiliza este tema (como en el área de la cantada Fogosa inteligencia, donde el tema presentado en R1 es completamente diferente al material expuesto en A1), lo habitual es que A1 retome el material temático expuesto en el primer ritornello (ya sea en su totalidad o solo el comienzo). 
Por otra parte, R1 suele ser una sección estable en lo que a rasgos armónicos se refiere, ya que se encarga de presentar la tonalidad principal y, aunque A1 comienza frecuentemente en este tono principal (ya establecido en R1), termina en una tonalidad contrastante tras una serie de modulaciones. Antes de continuar exponiendo las peculiaridades tonales de las áreas analizadas, y para comprender mejor todo lo referente al planteamiento tonal de estas secciones, podemos observar la siguiente tabla:

TABLA 4. ESTRUCTURA INTERNA DE LAS ÁREAS Y PRINCIPALES ZONAS TONALES

\begin{tabular}{|l|l|l|l|l|l|l|}
\hline \multicolumn{1}{|c|}{ A } & & & & & \multicolumn{1}{c|}{ B } & A' (“d. C.") \\
\hline $\begin{array}{l}\text { R1 } \\
\begin{array}{l}\text { Tono } \\
\text { principal. }\end{array}\end{array}$ & $\begin{array}{l}\text { A1 } \\
\text { Paso del tono } \\
\text { principal al primer } \\
\text { tono contrastante }\end{array}$ & $\begin{array}{l}\text { R2 } \\
\text { Primer tono } \\
\text { contrastante. }\end{array}$ & $\begin{array}{l}\text { A2 } \\
\text { Vuelta del primer } \\
\text { tono contrastante } \\
\text { al principal. }\end{array}$ & $\begin{array}{l}\text { R3 } \\
\text { Tono } \\
\text { principal. }\end{array}$ & $\begin{array}{l}\text { B } \\
\text { Segundo tono } \\
\text { contrastante. }\end{array}$ & $\begin{array}{l}\text { A' ("d. C.”) } \\
\text { Repetición } \\
\text { de A. }\end{array}$ \\
\hline Ej. 1: Sol M & Ej. 1: Sol M a Re M & Ej. 1: Re M & Ej. 1: Re M a Sol M & Ej. 1: Sol M & Ej. 1: Mi m & \\
\hline Ej. 2: La m & Ej. 2: La m a Do M & Ej. 2: Do M & Ej. 2: Do M a La m & Ej. 2: La m & Ej. 2: Do M & \\
\hline
\end{tabular}

En la zona B de estas áreas se establece una nueva polaridad armónica en la que, de un tono mayor al comienzo (sección A), generalmente en B pasamos al relativo menor y viceversa; por tanto, ambas tonalidades están emparentadas por una distancia de tercera ${ }^{74}$. Comprobamos entonces que tonalmente se produce un segundo contraste en la pieza al llegar a la sección B y, además, este cambio no es solo armónico, sino que varios parámetros musicales pueden verse alterados.

Hasta mediados del s. XVIII casi todas las áreas analizadas solían mostrar una mayor cohesión entre A y $\mathrm{B}$ en lo que a aspectos temáticos, textura o tempo se refiere $^{75}$, pero Iribarren acentuó este contraste seccional a partir de 1751, afectando a otro tipo de parámetros: el material temático normalmente es diferente melódica y

74. Aunque lo habitual es que, como ya hemos señalado, B pase al relativo mayor en áreas que comienzan en tono menor y viceversa, encontramos casos en los que esta sección B se inicia enfatizando la subdominante antes de pasar al relativo mayor o menor, hecho observable en las áreas de las cantadas Hasta aqui Dios amante, Qué temprano joh! bien mío y Hola chequillo. Por otra parte, hallamos un caso en el que B pasa al homónimo mayor, como en el área de la cantada Ya anticipo la alegre primavera, donde el tono principal era sol menor y en $\mathrm{B}$ se produce un cambio de armadura que nos lleva a sol mayor.

75. Es frecuente encontrar el mismo material temático que aparecía en R1 o A1 y, aunque melódicamente variasen algunos intervalos, el perfil rítmico de la melodía solía mantenerse. 
rítmicamente ${ }^{76} \mathrm{y}$, además, puede producirse un cambio de tempo $o^{77}$ o el empleo de algún recurso sonoro que produzca un contraste con lo anterior ${ }^{78}$. Por otra parte, en el acompañamiento de la voz principal de B también se observa una evolución, ya que a partir de 1751 hay casos en los que se reduce su presencia y emplea figuraciones más lentas ${ }^{79}$, como el que mostramos a continuación:

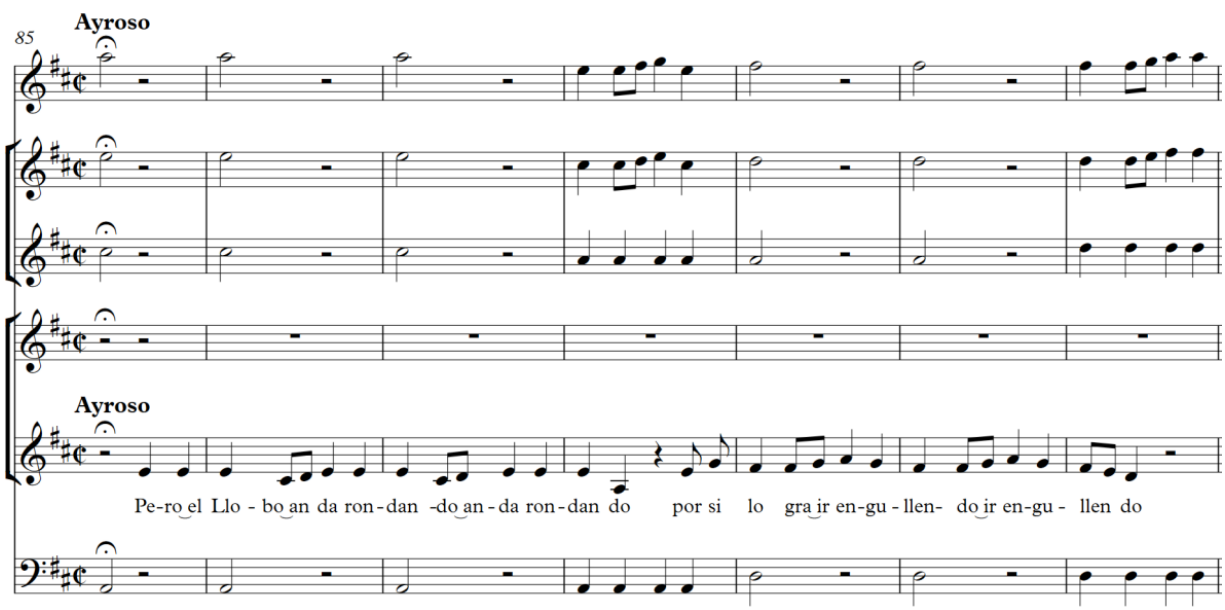

Ilustración 5. Sección B (cc. 85-91) del área de la cantada Hola Jau ah Riselo.

Armónicamente, la sección B es bastante modulante en términos generales, a pesar de contar con una longitud menor, si la comparamos con otras partes como A1 o A2. Aunque no encontramos ningún patrón común, la tonalidad con la que finaliza es bastante significativa: cuando esta sección B está en un tono mayor, tras un proceso modulante, concluye en este mismo tono mayor; pero si,

76. Respecto a este contraste entre los materiales temáticos de una pieza, Charles Rosen menciona la contraposición entre las secciones A y B que se produce en la forma sonata. Este investigador afirma que Haydn solía utilizar en sus sonatas un solo tema, mientras Mozart prefería marcar el cambio a la dominante con un nuevo motivo enteramente nuevo y, con Beethoven, el segundo tema que señalaba el cambio armónico constituía una clara variante del tema inicial de la obra. Rosen, Charles. El estilo clásico: Haydn, Mozart, Beethoven. Madrid: Alianza Música, 2003, p. 38.

77. En el área de la pieza Hola Jau ab Riselo la sección A es "Amoroso", mientras que B es "Airoso".

78. En el área de la cantada Ya job! gran naturaleza aparece el efecto del "punteado» en los violines y acompañamiento al llegar a la sección B, lo que podría ser el equivalente del pizzicato actual.

79. Charles Rosen comenta que la sección B en un aria da capo suele ser más breve, más expresiva, y puede contrastar con la sección A mediante un cambio de modo, pero es mucho más habitual mediante una reducción de la potencia. A veces la orquesta en esta sección se reduce a un simple bajo continuo. Rosen, Charles. Formas de sonata. Madrid: Mundimúsica Ediciones, 2010, p. 29. 
por el contrario, B está en un tono menor, estas modulaciones nos conducirán a la tonalidad de la dominante. Para apreciar mejor estos dos procesos armónicos, podemos observar la siguiente tabla:

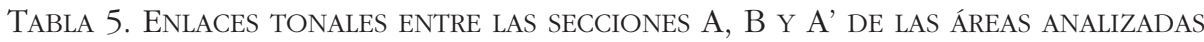

\begin{tabular}{|c|c|c|}
\hline A & B & A $^{\prime}$ \\
\hline $\begin{array}{c}\text { Tono mayor } \\
\text { Ej.: Do M }\end{array}$ & $\begin{array}{c}\text { Relativo menor } \\
\text { (finalizando en la dominante) } \\
\text { Ej.: La m (Mi) }\end{array}$ & $\begin{array}{c}\text { Tono mayor } \\
\text { Ej.: Do M }\end{array}$ \\
\hline $\begin{array}{c}\text { Tono menor } \\
\text { Ej.: La m }\end{array}$ & $\begin{array}{c}\text { Relativo mayor } \\
\text { (finalizando en tónica) } \\
\text { Ej.: Do M (Do) }\end{array}$ & $\begin{array}{c}\text { Tono menor } \\
\text { Ej.: La m }\end{array}$ \\
\hline
\end{tabular}

En las casuísticas reflejadas en la tabla anterior, Iribarren buscaba con asiduidad un enlace concreto entre B y A': un descenso de tercera para unir el final de la sección B con el comienzo de A'. Y no parece ser una casualidad, ya que este maestro de capilla recurría de manera vehemente a este intervalo descendente, salvo contadas excepciones ${ }^{80}$, tanto en obras que estuviesen en tono mayor como en menor. Es probable que la numerología musical diese alguna explicación plausible a este fenómeno, ya que el número tres suele tener una fuerte connotación religiosa (emparentado con símbolos como la Santa Trinidad o los tres Reyes Magos); además, que este paso tonal siempre sea descendente también comparte relación con la festividad para la que están escritas estas piezas (el Nacimiento de Jesucristo y su descenso de los Cielos a la Tierra). Estas son composiciones de una gran simbología religiosa y, aunque en el presente estudio nos resulta imposible indagar en este asunto, no queríamos dejar de lado esta pincelada mística en nuestro análisis, relacionando datos musicales con religiosos ${ }^{81}$.

Retomando aspectos puramente formales, podemos añadir que, aunque las secciones $\mathrm{B}$ de estas áreas no presentan ningún esquema interno recurrente, sí que hay algunos casos en los que estas terminan con una breve sección que denominaremos codetta. La mayoría de estos breves epílogos tienen lugar tras

80. Este fenómeno no sucede, por ejemplo, en el área de la cantada Por aquel horizonte.

81. Miriam Gómez-Morán analiza en detalle la simbología subyacente en obras de Liszt, pues, según palabras de este polifacético autor romántico, "el compositor de música de la iglesia es, a la vez, predicador y sacerdote, y lo que la palabra no consigue hacer llegar a nuestra percepción, el sonido lo convierte en alado y claro». Gómez-Morán, Miriam. "La música religiosa de Liszt». Revista de Espiritualidad, 2008, 67, p. 371. Otro estudio relacionado con la simbología latente en la música es GoDwIN, Joscelyn. Armonías del cielo y de la tierra: la dimensión espiritual de la música desde la Antigüedad hasta la Vanguardia. Barcelona: Ediciones Paidós, 2000. 
un calderón y, a su vez, esta parada del discurso musical suele coincidir con una armonía suspensiva, ya sea un acorde de séptima sobre la sensible, una tónica en segunda inversión, una dominante o un sexto grado precedido por una dominante (cadencia rota). Esta breve sección no excede de los cuatro compases y, en muchas ocasiones, supone un cambio de tempo marcado con un adagio. Del mismo modo que la velocidad del discurso musical se reduce, la instrumentación también sufre una disminución y, en obras cuya plantilla está formada por instrumentos de viento o de cuerda, estos suelen desaparecer o reducir su presencia para dejar protagonismo a la voz acompañada solo por el bajo continuo.

Esta breve sección no es un mero añadido, ya que armónicamente la frase no está resuelta antes de la codetta y, además, en algunas ocasiones la parada se produce rompiendo una palabra, lo que nos lleva a pensar que este era un lugar idóneo para la inclusión de alguna cadencia vocal improvisada. En el caso del área de la cantada Por aquel horizonte, este embellecimiento melódico sería anotado por el propio Iribarren al final de la sección B, especificando al encargado de escribir las particellas que «esto se copia en un punto más tenue fuera del área en la VOZ", como podemos ver en la siguiente imagen:

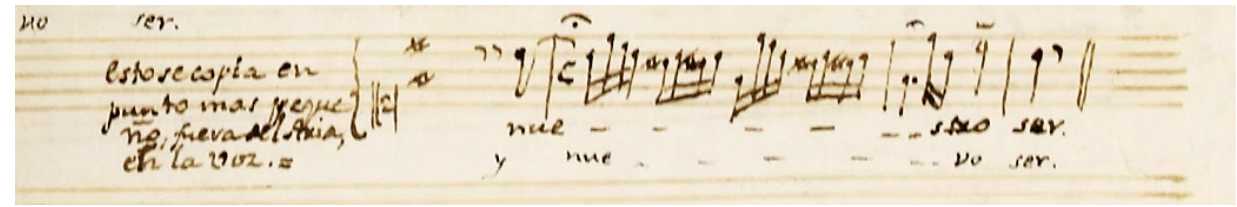

Ilustración 6. Cadencia escrita por el propio Iribarren al final del área de la cantada Por aquel horizonte. Manuscrito de la partitura general. A.C.M., leg. 295 (sección música).

Dado que, además del manuscrito general, también se conservan las particellas de esta pieza, hemos corroborado que el copista acató la orden del maestro. Como se observa en la siguiente ilustración, este anotó dicho pasaje improvisatorio en la particela de la voz de tiple.

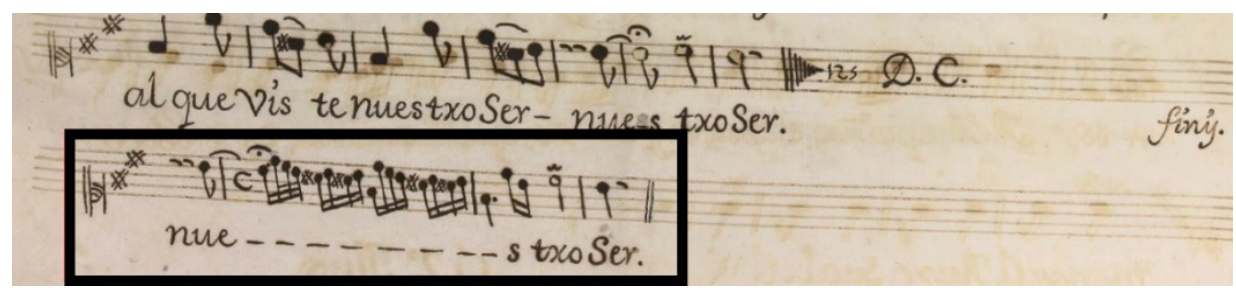

Ilustración 7. Últimos compases del área de la cantada Por aquel horizonte. Particella de la voz de tiple. A.C.M., leg. 295 (sección música). 
La citada pieza fue trascrita por Miguel Querol, pero detalles de este tipo no fueron reflejados en su edición ${ }^{82}$. Esto nos hace reflexionar sobre una importante premisa a la hora de estudiar este tipo de repertorio: las fuentes originales muestran muchos aspectos que pueden pasar desapercibidos a simple vista, y no debemos desdeñar ningún tipo de anotación por nimia que pueda parecer.

En cuanto a la ornamentación, no existen demasiados datos sobre el nivel técnico general de los cantantes y ministriles durante el Barroco, pero sabemos por los tratados que se valoraba sobremanera el "echar glosas", la "gala» y la "garganta" ${ }^{83}$. Se apreciaban las vocalizaciones (lo que en los textos de la época se denominaba "glosa de garganta» o "gala»), los agudos, los ornamentos o "quiebros", la inteligibilidad y expresión del texto, la sensación de ausencia de esfuerzo y el no descomponer el gesto, además de otra serie de habilidades ${ }^{84}$. El porqué de estas destrezas exigidas se encuentra en la tendencia imperante durante el Barroco a insertar cadencias vocales en la mayoría de las arias y, asimismo, a ornamentar la sección da capo de la pieza; este tipo de añadidos debía ser diferente en cada interpretación, aunque, en el caso de la pieza Por aquel horizonte, Iribarren opta por dejar escritas las notas exactas de esta cadencia ${ }^{85}$.

Si retomamos los aspectos formales ya mencionados, debemos puntualizar que, aunque la mayoría de las áreas de Iribarren aquí analizadas se ciñen a una macroforma tripartita que, a su vez, sigue una microforma pentapartita, encontramos bastantes excepciones; es más, por muchas generalizaciones que intentemos hacer sobre el estilo compositivo de este autor, siempre encontramos casos singulares u originales. Aunque se mostraba cómodo siguiendo ciertos cánones formales, parece que la creatividad de este maestro de capilla le hacía evitar en ciertos momentos estas estructuras o planes tonales prefijados, pues casi todas las piezas contienen alguna excepción que las aleja en mayor o menor medida de marcos compositivos habitualmente asumidos en su época.

Además del ejemplo anteriormente mencionado, también citaremos el área de la cantada Ya job! gran naturaleza que, aunque también se trata de un área pentapartita común, la diferencia reside en la inserción de varias secciones con un tempo, instrumentación, compás y figuración rítmica diferente. Esta combinación de secciones contrastantes está vinculada al texto, ya que este sufre un cambio en su contenido. De hecho, tanto A1 como A2 combinan dos secciones internas contrastantes conectadas con el significado del texto, tal y como se ilustra a continuación:

82. Querol Gavaldá, Miguel (ed.). Música barroca española (vol. 5): Cantatas y canciones para voz solista e instrumentos..., op. cit., pp. 59-67.

83. GONZÁlEz MARÍn, Luis Antonio. «Aspectos de la práctica musical española en el s. XVII: voces y ejecución vocal». Anuario Musical, 2001, 56, p. 90.

84. Ibid., pp. 92-93.

85. Para más información sobre convenciones interpretativas relacionadas con la ornamentación, véase Hill, John Walter. La música barroca. Madrid: Ediciones Akal, 2010, p. 411. 
JUAN FRANCÉS DE IRIBARREN: CANTADAS DE NAVIDAD Y REYES PARA TIPLE DURANTE SU MAGISTERIO...

TABla 6. Estructura FORMAL DE LA CANTADA YA jOH! GRAN NATURALEZA

\begin{tabular}{|c|c|c|c|c|c|c|}
\hline \multicolumn{5}{|c|}{ A } & B & $\mathrm{A}^{\prime}$ \\
\hline $\begin{array}{l}\text { R1 } \\
\text { cc. } 1-17\end{array}$ & $\begin{array}{l}\text { A1 } \\
\text { cc. 18-67 }\end{array}$ & $\begin{array}{l}\text { R2 } \\
\text { cc. } 68-72\end{array}$ & $\begin{array}{l}\text { A2 } \\
\text { c. } 73-122\end{array}$ & $\begin{array}{l}\text { R3 } \\
\text { CC. 123-126 }\end{array}$ & $\begin{array}{l}\text { B } \\
\text { cc. 127-148 }\end{array}$ & \\
\hline $\begin{array}{l}\text { Amoroso } \\
3 / 4 \text { cc. } 1-43\end{array}$ & $\begin{array}{l}\text { Airoso } \\
\text { cc. } 44-7\end{array}$ & & $\begin{array}{l}\text { Amoroso 3/4 } \\
\text { cc. } 73-107\end{array}$ & $\begin{array}{l}\text { Airoso C } \\
\text { cc. } 108-126\end{array}$ & $\begin{array}{l}\text { Amoroso } \\
3 / 4 \text { cc. } 127-148\end{array}$ & \\
\hline
\end{tabular}

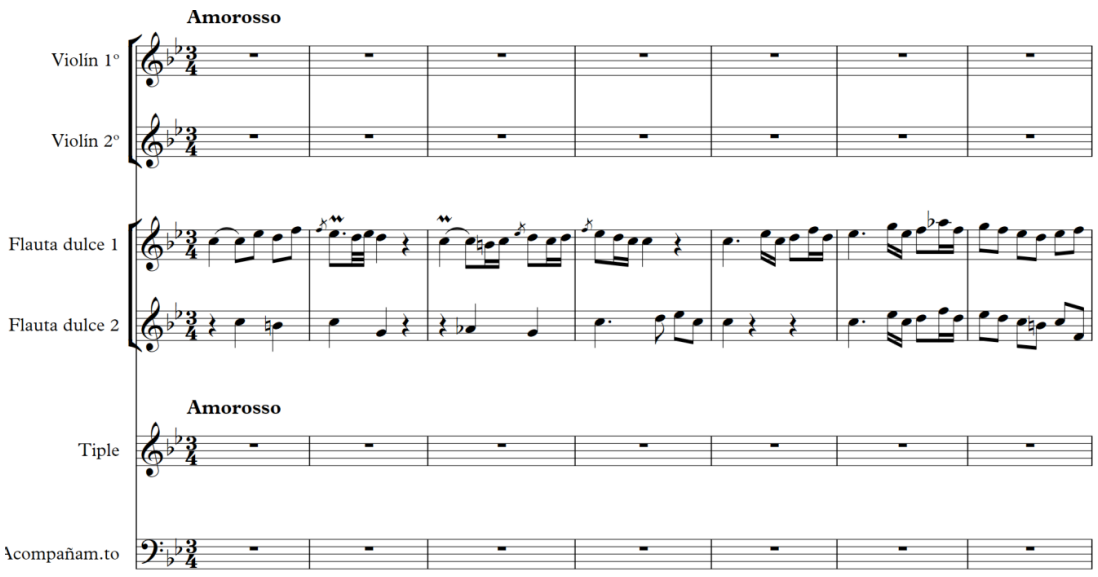

Ilustración 8. Área de la cantada Ya joh! gran naturaleza (cc. 1-7).
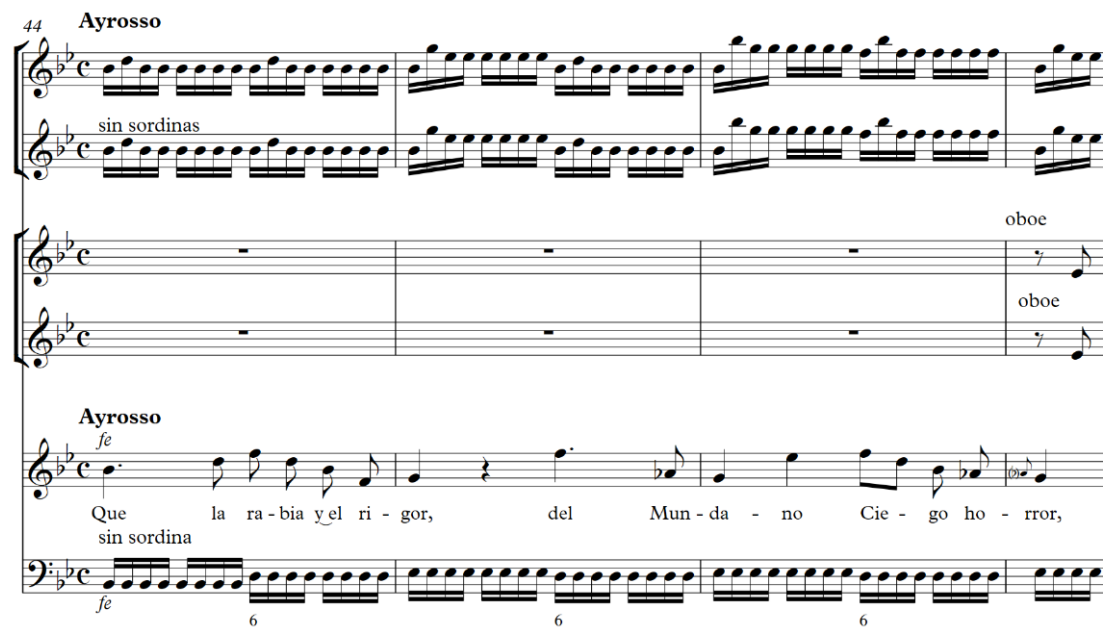

Ilustración 9. Área de la cantada Ya joh! gran naturaleza (cc. 44-47). 
En la siguiente tabla observamos que el poema de esta área describe dos atmósferas diferentes: la primera es calmada, con adjetivos como «dulces», "mansos» y "suaves», que coincide musicalmente con el tempo «amoroso» en compás ternario (3/4) y el predominio rítmico de corcheas o negras, a lo que se suma el empleo de sordinas en violines y acompañamiento; y la segunda es agitada, con sustantivos como "rabia", "rigor", "horror", "guerra" y "tempestad", en la que pasamos a un "airoso", sin sordina en violines y acompañamiento, en compás cuaternario, donde las semicorcheas son las figuras más empleadas. La instrumentación también es un recurso diferenciador, puesto que la presencia de la flauta y el empleo de sordina en los violines en el "amoroso» contrastan con la aparición del oboe en el «airoso» y, asimismo, la interpretación sin sordina en los instrumentos de cuerda.

\section{TABla 7. TeXTo Del ÁREA DE LA CANTADA YA ¡OH! GRAN NATURALEZA} Y SU CORRESPONDENCIA CON LA ESTRUCTURA FORMAL

\begin{tabular}{|l|l|l|}
\hline \multicolumn{1}{|c|}{ TEXTO } & INDICACIÓN DE TEMPO & SECCIÓN MUSICAL \\
\hline $\begin{array}{l}\text { Tiernas flores dulces aves, } \\
\text { arroyuelos mansos vientos, } \\
\text { inspirad vuestros acentos, } \\
\text { ya sonoras ya suaves, } \\
\text { a este solo Dios de amor, }\end{array}$ & Amoroso & A1 y A2 \\
\cline { 1 - 2 } $\begin{array}{l}\text { que la rabia y el rigor, } \\
\text { del mundano ciego horror, } \\
\text { forma guerra y tempestad. }\end{array}$ & Airoso & \\
\hline
\end{tabular}

También citaremos el caso del área de la cantada Hola Jau ab Riselo, cuyo esquema formal es uno de los más originales (ver Tabla 8). Si tenemos en cuenta la estructura general de las áreas analizadas, se observan varias diferencias significativas: primeramente, en la sección A de la cantada Hola Jau ab Riselo se omite un ritornello instrumental (R3) y, sin embargo, se incluye otra sección vocal (A3) que hace las veces de transición; por otra parte, Iribarren no escribió da capo tras la sección $\mathrm{B}$, sino que esta reexposición aparece escrita y muy simplificada, pues excluye varias secciones internas (prescinde de la repetición de todas las secciones instrumentales y de A3), dando como resultado una reexposición selectiva mucho más reducida.

Tabla 8. Estructura Formal del área de la cantada Hola JaU aH Riselo

\begin{tabular}{|c|c|c|c|c|c|c|c|}
\hline \multicolumn{5}{|c|}{ A } & B & \multicolumn{2}{|c|}{$A^{\prime}$} \\
\hline \multicolumn{5}{|c|}{ Amoroso 3/4 } & Airoso C & $\mathrm{Am}$ & \\
\hline $\mathrm{R} 1$ & A1 & A2 & $\mathrm{R} 2$ & A3 & B & A1 & $\mathrm{A} 2$ \\
\hline
\end{tabular}




\subsection{Otros movimientos o secciones}

Pese a tratarse de secciones mucho menos recurrentes que los recitados o áreas, en las cantadas analizadas también aparecen varias introducciones y, solo en uno de los casos, una "pastorela". Respecto a las introducciones o entradas ${ }^{86}$, estas secciones no muestran un plan formal específico, sino una estructura interna algo aleatoria. Aunque Iribarren no empleaba estos movimientos o secciones introductorias con gran frecuencia en las cantadas analizadas, lo cierto es que estos sí fueron muy utilizados por otros autores coetáneos como Antonio Soler, de cuyos ciento veinticinco villancicos, analizados por Paulino Capdepón, noventa y cuatro comienzan por una introducción ${ }^{87}$.

Por otra parte, solo una de las piezas analizadas de Iribarren contiene un movimiento denominado "pastorela». Este tipo de secciones, a grandes rasgos, estaban escritas en 6/8 o 12/8, predominaban formulaciones rítmicas como la corchea con puntillo, semicorchea más corchea, notas pedales, armonías simples, bajos repetitivos, un tempo moderado y, aunque podían estar presentes en villancicos de otras festividades, normalmente las pastorelas aparecían en los ciclos de Navidad $^{88}$. Álvaro Torrente también hacía referencia a este tipo de secciones, resaltando el ritmo alla siciliana (6/8 con un puntillo en la primera corchea de cada tres) y las terceras y sextas paralelas tan características en los instrumentos agudos, que imitaban la rusticidad de la música pastoril (rasgo también denominado stylus rusticanus fuera de España) ${ }^{89}$.

En el caso de la pastorela compuesta por Iribarren, esta cumple con gran parte de estas premisas, pues está compuesta en un compás de 12/8 recurre reiteradamente al esquema rítmico de corchea con puntillo, semicorchea y corchea emplea notas tenidas o movimientos melódicos repetitivos en el bajo; una armonía sencilla; y un movimiento paralelo de las voces a distancia de tercera o sexta ${ }^{90}$. Un rasgo llamativo de esta sección es la ausencia de señalización de tempo; pero, según José Herrando, el término "pastorela" era una indicación de tempo o "aire»

86. Ampliando el estudio al resto de sus cantadas de Navidad y Reyes, se observa que en sus obras más tempranas utiliza el término «introducción", mientras que en sus piezas más tardías emplea el de "entrada».

87. Capdepón Verdú, Paulino. El P. Antonio Soler y el cultivo del villancico en El Escorial. Madrid: Ediciones Escurialenses, 1993, p. 69.

88. Ramos LóPEz, Pilar. "Pastorelas and the pastoral tradition in 18th Century Spanish villancicos». En Knighton, Tess y Torrente, Álvaro (eds.). Devotional music in Iberian world, 1450-1800. The villancico and related genres. EE. UU.: Ashgate Publishing Company, 2007, pp. 289-290 y 304-305.

89. TORRENTE SÁNCHEZ-GuISANDE, Álvaro. "La modernización/italianización de la música sacra»..., op. cit., p. 133.

90. La trascripción de esta pieza se halla publicada en SÁnCHEZ, Marta. XVIII Century Spanish Music: Villancicos of Juan Francés de Iribarren. Pittsburg: Latin American Literary Review Press, 1988. 
en sí mismo, de ahí que no fuese necesario especificar la velocidad o carácter con el que había de ser interpretada esta sección ${ }^{91}$.

\section{ASPECTOS LITERARIOS DE LAS OBRAS SELECCIONADAS}

En relación al registro lingüístico que se emplea en las piezas analizadas, Cristóbal García señalaba que las cantadas de este Iribarren no mostraban numerosos recursos populares $^{92}$. Además, sostenía que el estilo o registro popular era más frecuente en sus villancicos; mientras que las cantadas contaban con refinados protagonistas de procedencia mitológica ${ }^{93}$. Por otra parte, Marcelino Díez, tras examinar los textos de una selección de cantadas del s. XVIII conservadas en la catedral de Cádiz, afirmaba que en estas letras primaba un tono serio, excluyendo contenidos cómicos y burlescos ${ }^{94}$.

Sorprendentemente, en algunas de las piezas analizadas en este artículo se observa la presencia de dialectos, jergas o variantes lingüísticas diversas, hecho que contrasta con los postulados de los estudios mencionados anteriormente. Incluso, en muchas de las cantadas elegidas para el presente análisis, observamos la filtración de un lenguaje con claras reminiscencias populares que, sin embargo, no se identifica con ningún dialecto concreto.

A pesar de que el estudio de estos textos presenta una gran dificultad a nivel ecdótico, puesto que las distintas lenguas o jergas han sufrido mucha variación en su transmisión textual ${ }^{95}$, hemos identificado algunas variantes lingüísticas concretas, como son el sayagués y el italiano. El primero está en las cantadas Que habréis primero, Hola Jau ab Riselo y Pardiobre. Originalmente, este fue un dialecto leonés rudimentario que se hablaba en Sayago (provincia de Zamora); poco después, dicho término también pasó a designar el habla rural de Salamanca o charro, jerga muy característica por su tosquedad; Lucas Fernández, Juan del Encina, Lope de Rueda o Lope de Vega emplearon esta forma dialectal para reforzar el carácter humorístico en algunas de sus obras ${ }^{96}$. Así, el sayagués se convirtió en una jerga

91. La pastorela era un tipo de aire como también podían serlo Allegro, Allegreto, Andante, Adagio, Grave, Spiritoso, Presto o Andantino. Herrando, José. Arte y puntual explicación del modo de tocar el violín con perfección. París: 1757, p. 7.

92. GARCía GALLARDO, Cristóbal L. La cantada religiosa de Juan Francés de Iribarren (1698-1767): análisis de Sagrada Devoción (1757). Granada. Trabajo inédito de los cursos de doctorado, 1998, p. 32.

93. García Gallardo, Cristóbal L. "Villancicos del s. XVIII en España»..., op. cit., p. 87.

94. Los textos de estas cantadas estudiadas por Marcelino Díez se conservan en la BNE (Biblioteca Nacional de España), impresos en sus respectivos pliegos. Todos ellos se corresponden con villancicos cantados en la catedral de Cádiz en el s. XVIII. Dítz MarTínez, Marcelino. La música en Cádiz: la catedral y su proyección urbana durante el siglo XVIII. Cádiz: Servicio de Publicaciones de la Universidad de Cádiz y Servicio de Publicaciones de la Diputación de Cádiz, 2004, p. 448.

95. CANONICA, Elvezio. "Del pecado plurilingüe a la absolución monolingüe. La Farsa del sacramento, llamada de los lenguajes». Criticón, 1996, 66-67, p. 370.

96. VAlbuena Briones, Ángel. "Los papeles cómicos y las hablas dialectales en dos comedias de Calderón». Thesaurus, 1987, 1, 42, p. 48. 
artificial de los pastores, adquiriendo estos el papel de «bobos» o campesinos ignorantes que, sin embargo, rebosaban de sentido común ${ }^{97}$. En cuanto a sus características fonéticas, Esther Borrego sostiene que la palatización inicial del fonema /1/ era uno de los rasgos típicos de esta variante lingüística; a esto hay que añadir los rotacismos o la vacilación vocálica, vulgarismos que pretendían la carcajada del público y mostraban la escasa cultura o bajeza de los personajes, así como onomatopeyas, formas apocopadas, frases hechas o sustitución de ciertos fonemas ${ }^{98}$.

Por otra parte, el empleo de la lengua italiana está presente en la cantada Per Maria gratia plena; en ella, el poeta ha querido emular el habla (algo vulgarizada) de un personaje italiano con una clara intención humorística. Tal y como señala Generosa Rey, en la mayoría de los casos de piezas que emplean variantes lingüísticas, como las anteriormente citadas, solo se trata de lenguas parodiadas con una gran dosis de castellanización ${ }^{99}$.

Además de rasgos dialectales, en las composiciones analizadas se encuentran aspectos que demuestran la teatralización de este tipo de repertorio, pese a que su destino eran los templos y lugares sagrados. En el caso de la cantada Qué habréis primero, las onomatopeyas «exe, exe» son acompañadas de una aclaración sobre cómo debían interpretarse, pues este maestro de capilla indicaba en el manuscrito original de la pieza que el cantante debía simular estar «tosiendo».

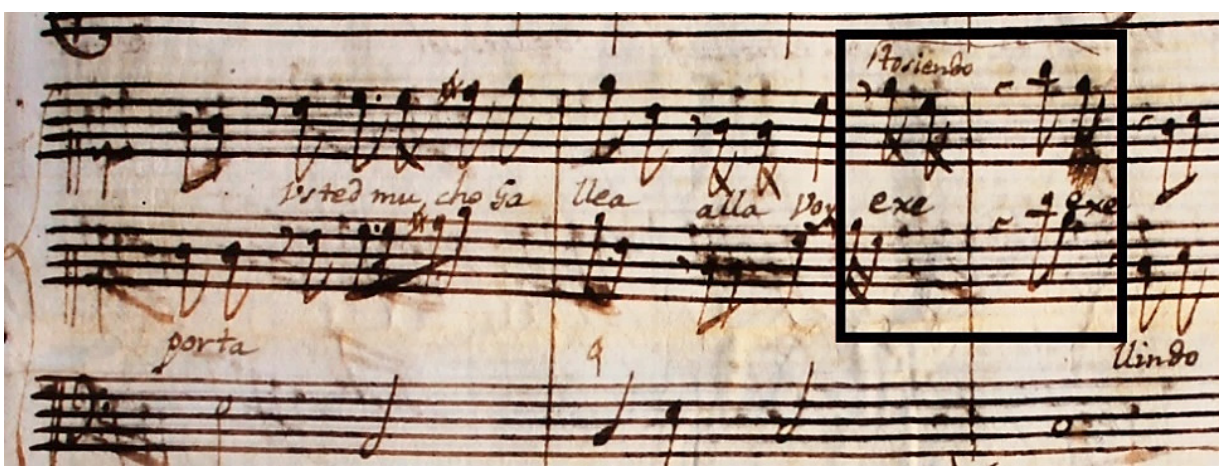

Ilustración 10. Segundo recitado de la cantada Qué habréis primero (cc. 6-8).

Parte de tiple 1, tiple 2 y acompañamiento del manuscrito general del autor. A.C.M., sig. 77-19 (sección música).

97. CANONICA, Elvezio. «Del pecado plurilingüe a la absolución monolingüe»..., op. cit., pp. 371-372.

98. Borrego Gutiérrez, Esther. "Edición crítica de los textos». En PeÑAlver, Guillermo y VillaRREAL, José Manuel (coords. y trascrip.). Juan Francés de Iribarren: cantadas para la catedral de Málaga. Sevilla: Universidad de Sevilla, 2011, p. 37.

99. REY SÁNCHEZ, Generosa. Lenguas y dialectos bispánicos en los villancicos del Siglo de Oro. Edición de villancicos españoles del s. XVII (1621-1700). Salamanca. Tesis doctoral, 2010, p. 18. 
Por último, no podemos desatender el análisis métrico de los textos que conforman estas piezas musicales. A grandes rasgos, en sus introducciones encontramos una gran aleatoriedad tanto métrica como estrófica, con versos que abarcan desde cinco hasta once sílabas. En el caso de la introducción de la cantada A Belén caminad, se observa la presencia de cuatro versos, decasílabos y hexasílabos, con rima asonante en los pares:

\author{
A Belén caminad pastorcillos, \\ que hay dos maravillas, \\ pues recreo común son de todos, \\ Jesús y María. \\ (Introducción de la cantada A Belén caminad)
}

Mientras, en sus recitados aparecen versos heptasílabos o endecasílabos y, esporádicamente, de cinco sílabas, que están estructurados en sucesiones de pareados, sexta rima o la combinación de pareados con otra serie de estrofas (cuartetos y liras). Como ejemplo citaremos el recitado de la cantada Per Maria gratia plena, formado por un grupo de pareados heptasílabos y endecasílabos; y el de la cantada $A$ Belén caminad, que muestra la sexta rima en su sucesión de versos endecasílabos:

\author{
Yo porto piu atontato, \\ di ver il sol vestito di incarnato \\ may piacheri mi da que la visione, \\ chi un plato di pollastra e macarrone, \\ la note fà dileto, \\ il hipocras rossoli españoleto. \\ (Recitado de la cantada Per Maria gratia plena) \\ Dulces ternezas que el amor inflama, \\ finos cariños que el placer explica, \\ entre hijo y madre con piadosa llama, \\ la más ardiente unión se especifica, \\ pues uno a otro en fiel correspondencia, \\ se aplauden el favor y la clemencia. \\ (Recitado de la cantada A Belén caminad)
}

En cuanto a las áreas, por lo general se evitan metros largos, siendo los octosílabos empleados de manera recurrente. No obstante, también aparecen versos de cinco, seis, siete o diez sílabas de manera algo esporádica. Como ejemplo citaremos el área 1 de la cantada Fogosa inteligencia, formada por dos quintillas hexasilábicas; el área de la cantada Por aquel horizonte, que responde a una copla real; y el área 2 de la cantada Fogosa inteligencia, cuyo patrón estrófico se corresponde con un sexteto paralelo: 


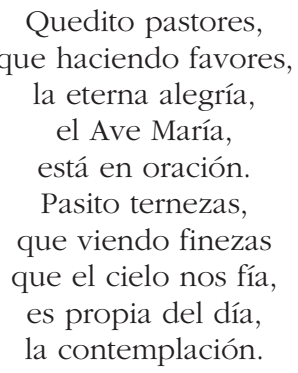

(Área 1 de la cantada Fogosa inteligencia)

Todo el mundo en alborozo, manifieste su contento, mansa el aura suave el viento, acompañe el gusto y gozo, que resuena hoy en Belén. En la cuna de un pesebre y en los brazos de la aurora, como a sol que cumbres dora, tierno afecto le celebre, al que viste nuestro ser.

(Área de la cantada Por aquel horizonte)

Ya borrascas el hombre no tema, que hoy le viene la dicha suprema en los brazos del iris de paz.

Parabienes se den los mortales, cuando nace con finas señales, el motivo de todo solaz.

(Área 2 de la cantada Fogosa inteligencia)

Por último, la única pastorela presente en sus cantadas de Navidad y Reyes analizadas responde a un patrón concreto: el romancillo hexasilábico.

\author{
Celebren pastores, \\ con júbilo igual, \\ en hijo y en madre, \\ belleza y piedad. \\ Mostrando gozosos, \\ que está en el portal, \\ en uno y en otro, \\ la gloria y la paz.
}

(Pastorela de la cantada A Belén caminad) 


\section{CONCLUSIONES}

El presente artículo supone un estudio multidisciplinar en el que confluyen datos históricos, musicales y literarios; esta triple dimensión nos permite mostrar con mayor rigor las características de estas cantadas para Navidad y Reyes seleccionadas. Puesto que solo hemos incluido aquellas piezas compuestas para voz de tiple, resultaba apremiante conocer la realidad musical de la capilla durante aquella época; así, hemos comprobado que la ausencia de tiples en plantilla durante su magisterio no supuso óbice para que Iribarren dedicara cantadas de Navidad y Reyes a este registro vocal, aunque para ello tuviese que valerse de otros miembros de la capilla.

En cuanto a aspectos estrictamente musicales, en muchas ocasiones la frontera entre el término "villancico» y "cantada» en su obra está algo difuminada, llegando el propio Iribarren a usar ambos de manera indiferente. Es más que probable que, como hemos señalado en epígrafes anteriores, la denominación elegida para estas piezas atendiese más a su función en la liturgia que a su forma musical, de ahí que las cantadas en muchas ocasiones fuesen denominadas con el término "villancico", pues estas eran simplemente una variante con unas características formales concretas.

Dado que las piezas analizadas abarcan un largo periodo temporal en la vida compositiva de Iribarren (1733-1759), dichas composiciones son reflejo de la evolución estilística que se produce durante el s. XVIII ${ }^{100}$. En ellas queda patente el paso de la forma monotemática a la bitemática y, asimismo, se aprecia una simplificación en lo que a número de movimientos o secciones se refiere, hecho que coincide con otros compositores coetáneos ${ }^{101}$.

En cuanto al análisis formal de sus obras, se han detectado patrones formales o tonales recurrentes en las áreas de sus cantadas de Navidad y Reyes de tiple, respondiendo estas, por lo general, a una forma interna pentapartita. No obstante, su capacidad musical supera cualquier férrea tendencia estructural que imperase

100. Luis Naranjo señala que en la etapa compositiva más temprana de Iribarren se observa la presencia de una gran cantidad de recursos polifónicos, contrapuntísticos y tímbricos contrastantes, más comunes en la estética barroca, mientras que en los últimos años su obra opta por una mayor simplicidad y melodías diáfanas y equilibradas, elementos más propios del estilo "galante», antecesor del Clasicismo. NARANJo Lorenzo, Luis E. «La aportación de Juan Francés de Iribarren en la música española del s. XVIII". Musiker, 1999, 11, p. 47. A esta mezcla de contrapunto barroco y recursos galantes en la obra de Iribarren se alude en Gembero UstáRroz, María. Navarra/Música. Navarra: Gobierno de Navarra, Departamento de Cultura, Deporte y Juventud y Dirección General de Cultura-Príncipe de Viana, 2016, pp. 132-133.

101. Marcelino Díez analizó la música de la catedral de Cádiz en el s. XVIII y observó este proceso de simplificación en las cantadas seleccionadas para su estudio; en 1731 solo una de ellas constaba de dos movimientos (recitado y aria), pero a partir de 1741 todas estarían formadas por dos. Díez Martínez, Marcelino. La música en Cádiz: la catedral y su proyección urbana durante el siglo XVIII..., op. cit., 2004, p. 449. 
en la época y, pese a estar familiarizado con las modas del momento, su estilo y recursos compositivos le convierten en un maestro de capilla con un criterio y personalidad muy singulares, de ahí los casos excepcionales que hemos encontrado en la estructura interna de algunas de sus áreas analizadas.

Los rasgos literarios más peculiares de estas obras los encontramos en el empleo de diversas variantes dialectales como el sayagués o el italiano; como hemos observado, Iribarren no quiso prescindir de este tipo de poemas que buscaban la hilaridad del público, confirmándose así la filtración de aspectos vulgares o coloquiales en las solemnes fiestas del culto divino. En cierta medida, estas piezas pretendían contentar a un público expectante que anhelaba el regocijo y disfrute; no olvidemos que esta música engalanaba la Nochebuena y acercaba la palabra divina al pueblo iletrado, usando jergas de clases bajas o recursos teatrales más propios del género dramático que del religioso. En cuanto al análisis estrófico, resulta evidente la riqueza literaria de estos textos, donde se recurría a una gran variedad de esquemas métricos que daban forma a sus versos.

Como último dato destacable queremos advertir a futuros investigadores sobre la necesidad de observar las piezas de este compositor con suma atención: Anotaciones que, a simple vista, pueden parecer irrelevantes, se convierten en el punto de partida de importantes interrogantes que nos ayudarán a reconstruir nuestro pasado musical.

\section{FUENTES MANUSCRITAS}

Archivo de la catedral de Málaga (A.C.M.).

En este archivo hemos consultado actas capitulares, legajos y las piezas objeto de estudio compuestas por Juan Francés de Iribarren (véase Tabla 1).

\section{Bibliografía}

Alvar EzQuerra, Manuel. Villancicos dieciochescos. Edición facsímil. Málaga: Ayuntamiento de Málaga, 1973.

BOnASTRE Bertrán, Francesc. "Els orígens del concepte de barroc musical hispànic, a l'entorn del centenari de l'Institut d'Estudis Catalans: Felip Pedrell, Higini Anglès, Miguel Querol». Recerca Musicològica, 2007-2008, XVII-XVIII, pp. 41-65.

Borrego Gutiérrez, Esther. «Edición crítica de los textos». En PeÑalver, Guillermo y VillaRREAL, José Manuel (coords. y trascriptores). Juan Francés de Iribarren: cantadas para la catedral de Málaga. Sevilla: Universidad de Sevilla, 2011, pp. 32-45.

CANONICA, Elvezio. «Del pecado plurilingüe a la absolución monolingüe. La Farsa del sacramento, llamada de los lenguajes». Criticón, 1996, 66-67, pp. 369-382.

CAPDePón Verdú, Paulino. El P. Antonio Soler y el cultivo del villancico en El Escorial. Madrid: Ediciones Escurialenses, 1993. 
CAPDEPÓN Verdú, Paulino. "Cantada». En CASARES Rodicio, Emilio (dir. y coord.). Diccionario de la música española e hispanoamericana. Madrid: Sociedad General de Autores y Editores, 1999, vol. 3, pp. 72-74.

Carreras López, Juan José. La música en las catedrales durante el s. XVIII. Francisco J. García "El Españoleto" (1730-1809). La Rioja: Institución Fernando el Católico, 1983.

Carreras lópez, Juan José. «La cantata española». En Leza CruZ, José Máximo (ed.). Historia de la música en España e Hispanoamérica (vol. 4). La música en el s. XVIII. Madrid: Fondo de Cultura Económica, 2014, pp. 171-191.

Díez MARTínez, Marcelino. La música en Cádiz: la catedral y su proyección urbana durante el siglo XVIII. Cádiz: Servicio de Publicaciones de la Universidad de Cádiz y Servicio de Publicaciones de la Diputación de Cádiz, 2004.

DODERER, Gerhard. "Un repertorio desconocido: las cantadas de Jayme de la Tê y Sagau (Lisboa, 1715-1726)». En Boyd, Malcolm y CarReras López, Juan José (eds.). La música en España en el s. XVIII. Madrid: Cambridge University Press, 2000, pp. 95-125.

García GallaRdo, Cristóbal L. La cantada religiosa de Juan Francés de Iribarren (1698-1767): análisis de Sagrada Devoción (1757). Granada. Trabajo inédito de los cursos de doctorado, 1998.

García Gallardo, Cristóbal L. «Villancicos del s. XVIII en España». Música y Educación, 2009, 80, pp. 78-91.

Gembero Ustárroz, María. Navarra/Música. Navarra: Gobierno de Navarra, Departamento de Cultura, Deporte y Juventud y Dirección General de Cultura-Príncipe de Viana, 2016.

GODWIN, Joscelyn. Armonías del cielo y de la tierra: la dimensión espiritual de la música desde la Antigüedad hasta la Vanguardia. Barcelona: Ediciones Paidós, 2000.

Gómez-Morán, Miriam. "La música religiosa de Liszt». Revista de Espiritualidad, 2008, 67, pp. 371-386.

GONZÁLEZ MARín, Luis Antonio. «Aspectos de la práctica musical española en el s. XVII: voces y ejecución vocal». Anuario Musical, 2001, 56, pp. 83-95.

GonZÁlez VAlle, José V. «Música litúrgica con acompañamiento orquestal, 1750-1800». En BOYD, Malcolm y Carreras LóPez, Juan José (eds.). La música en España en el s. XVIII. Madrid: Cambridge University Press, 2000, pp. 95-125.

HerRando, José. Arte y puntual explicación del modo de tocar el violín con perfección. París: 1757.

HiLl, John Walter. La música barroca. Madrid: Ediciones Akal, 2010.

JAMBOU, Louis. "Cantatas solísticas de Valls y compositores anónimos. Identidad y ruptura estilística. Apuntes para un estudio". Revista de Musicología, 1995, vol. 18, pp. 291-325.

LARA MORAL, Laura. Juan Francés de Iribarren: Las cantadas de Navidad de 1751. Trabajo final de máster inédito. Universidad de Granada, 2013.

LESTER, Joel. Compositional theory in the Eighteenth Century. Estados Unidos: Harvard University Press, 1996.

LESTER, Joel. Bach's Works for Solo Violin: Style, Structure, Performance. Nueva York: Oxford University Press, 1996.

López-CAlo, José. La música en las catedrales españolas. Madrid: Instituto Complutense de Ciencias Musicales, 2012.

MARTín MárQueZ, Alberto. Niños y tiples en la catedral de Zamora (1600-1750). Aproximación a su estudio. Zamora: Festival Internacional de Música "Pórtico de Zamora», 2008. 
MARTín QuiÑones, M. Ángeles. La música en la catedral de Málaga durante la segunda mitad del s. XVIII: La vida y obra de Jaime Torrens. Tesis doctoral inédita. Universidad de Granada, 1997.

Martínez Gil, Carlos. La capilla de música de la Catedral de Toledo (1700-1764): evolución de un concepto sonoro. Toledo: Junta de Comunidades de Castilla La Mancha, 2003.

NARANJO LORENZO, Luis E. Trascripción de una selección de la obra de Juan Francés de Iribarren (1699-1767): estudio preliminar y catálogo (inédito). Granada: Centro de Documentación Musical de Andalucía, 1997.

NARANJO LORENZO, Luis E. «La aportación de Juan Francés de Iribarren en la música española del s. XVIII». Musiker, 1999, 11, pp. 35-48.

Querol Gavaldá, Miguel (ed.). Música barroca española (vol. 5): Cantatas y canciones para voz solista e instrumentos (1640-1760). Barcelona: Instituto Español de Musicología, 1973.

Querol GAVALDÁ, Miguel. «El cultivo de la cantata en España y la producción musical de Juan Francés de Iribarren (1698-1767)». Cuadernos de Sección. Música, 1983, 1, pp. 115-128.

RAMOS LóPEZ, Pilar. "Pastorelas and the pastoral tradition in $18^{\text {th }}$ Century Spanish villancicos». En Knighton, Tess y Torrente, Álvaro (eds.). Devotional music in Iberian world, 1450-1800. The villancico and related genres. EE. UU.: Ashgate Publishing Company, 2007.

ReY SÁncheZ, Generosa. Lenguas y dialectos hispánicos en los villancicos del Siglo de Oro. Edición de villancicos españoles del s. XVII (1621-1700). Tesis doctoral inédita. Universidad de Salamanca, 2010.

Rosen, Charles. El estilo clásico: Haydn, Mozart, Beethoven. Madrid: Alianza Música, 2003.

Rosen, Charles. Formas de sonata. Madrid: Mundimúsica Ediciones, 2010.

SÁNCHEZ, Marta. XVIII Century Spanish Music: villancicos of Juan Francés de Iribarren. Pittsburg: Latin American Literary Review Press, 1988.

TORRENTE SÁNCHEZ-GUISANDE, Álvaro. "La modernización/italianización de la música sacra». En Leza Cruz, José Máximo (ed.). Historia de la música en España e Hispanoamérica (vol. 4). La música en el s. XVIII. Madrid: Fondo de Cultura Económica, 2014, pp. 125-156.

VALBUENA BRIONES, Ángel. «Los papeles cómicos y las hablas dialectales en dos comedias de Calderón». Thesaurus, 1987, 1, 42, pp. 47-59.

Westrup, Jack. "Recitativo». En SADIE, Stanley (ed.). The New Grove Dictionary of Music and Musicians. 6. ${ }^{a}$ edición. Londres: MacMillan Publishers Limited, 1980, vol. 15, pp. 643-648.

Westrup, Jack; McClymonds, Marita P.; Budden, Julian y Clemens, Andrew. «Aria». En SAdie, S. y TrRrel, J. The New Grove Dictionary of Music and Musicians [en línea], 2001 [consulta 22-10-19]. Disponible en: https://doi.org/10.1093/gmo/9781561592630. article.43315. 
